\title{
The comparative analysis of global pandemics of two respective genre
}

\begin{abstract}
The ongoing global pandemic that has been demolishing every aspect of humankind is truly unprecedented. The mankind experienced the variety of catastrophe since last few centuries, however, this deadly epidemic is extremely unique. This is not restricted to a particular geographical periphery, more importantly, it is not ethnicity dependent. If we could revert back, the last global epidemic of such proportion that is Spanish Flu (1918 $\mathrm{H} 1 \mathrm{~N} 1$ influenza pandemic) had plenty of similarities with the ongoing disaster in terms of the prevalence across the globe, epidemiology and associated attributes. Scientific fraternity across the world is trying the heart out to depict the origin of this deadly disaster but to say the least, there has been more argument than settlement. However, the most crucial part that coincidentally blends both the epidemics in a perfect order is the infodemic that without a shadow of doubt is the most staggering obstacle to deal with. In this paper a comprehensive effort has been put forward to illustrate the comparative analysis between the global pandemics of two respective genre. At the same time, the best possible lay outs have been also discussed to overhaul the ongoing crisis.
\end{abstract}

Keywords: pandemic, epidemic, infodemic, epidemiology, spanish flu
Volume 12 Issue 4 - 2020

\author{
Tapash Rudra \\ Lincoln University College, Selangor, Malaysia
}

Correspondence: Tapash Rudra, Associate Professor, Department of Biotechnology, Faculty of Science, Lincoln University College, Malaysia, Email tapashrudra@gmail.com

Received: July 15, 2020 | Published: August 27, 2020

\section{Introduction}

People are in pursuit of finding the correlation between the ongoing Covid-19 global pandemic and the other one of same stature that is none other than the Spanish Flu. To be honest, it does procure obvious perception as both the pandemics hold plenty of similar attributes. However, 1918 H1N1 Influenza pandemic lasted for around fifteen months or so, but the ongoing one is relatively minute regarding the time span is concerned. Any infection, irrespective of the causative agents relies heavily on the mode of dissemination among the hosts, followed by the community. In fact, the most common attribute that is relating the two respective pandemics of the different genre is the trajectory of the transmission. Both the 1918 H1N1 Influenza pandemic as well as the ongoing Covid-19 are adhering to the infection through respiratory droplets and the surface they reside. ${ }^{1}$ The pandemics of the respective genre under concern have substantially excelled into the development of practice of social distancing and complete closures of routine human activities. ${ }^{2}$ If we could have opened up the scenario a bit we would see that 1918 H1N1 Influenza pandemic documented the terms such as 'social distancing' in order to curtail down the'waves of diseases'. Eventually, that did happen, however, in three major spikes within the period of 1918-1919, taking the death toll to a havoc. ${ }^{3}$ Here lies the similarities of the ongoing deadly pandemic where people around the world are in a state of panic because there are significant possibilities of the resurgence in the future days to come. In other words, we might address that both the pandemics are remarkably similar in confusing the people across the globe regarding the 'flattening of the spike' is concerned.

\section{Epidemiological comparison between SARS-CoV-2 and I9I8 HINI virus}

It is the proven fact by now that both SARS-CoV-2 and H1N1 viruses are holding RNA as genetic material. In fact, RNA viruses typically lack the replication machineries to cross check the duplicated genes, leading to sizable changes. ${ }^{4}$ In other terms, by procuring such attributes they are more deadly both in terms of severity and prevalence irrespective of species and surface receptors they utilize. To be precise, 1918 H1N1 influenza virus carries the hereditary make up in terms of compacted or chunk genetic framework. They exhibit idiosyncrasy, meaning they share the total genetic material with the neighboring viruses leading to drastic change in evolutionary pathways. ${ }^{5}$ On the contrary, corona viruses do have the proof reading capabilities of the distorted RNAs in order to avoid the accidental errors of DNA replication. This is the principle reason behind the relatively lesser mutation rate of the respective corona viruses. If we could intricate more, we would be able to asses that SARS-CoV-2 comprises of less than 10 mutations among the 30,000 loci of its genome, even though, the virus has been disseminating across the globe irrespective of the ethnicity and races. On the same regard, however, 1918 H1N1 virus produces errors 6.5 folds more per replication cycle and that too is independent of the total genetic makeup. ${ }^{6}$ All in all, we can say by the notion of comparative genetic stability of SARS-CoV-2 that it is unlikely to have more number of mutations governed by natural selection pressure in the days to come. However, it is not beyond argument that there will not be the resurgence of waves of SARSCoV-2, especially, when people are about to take lenient measures by seeing the 'flattening the curve' in certain parts of the world.

\section{Seasonal influence on I9I8 HINI and SARS- CoV-2 virus}

Another extremely critical aspect of the comparability of the two global pandemics is seasonal variations and the subsequent influence. It is a well-known fact that $1918 \mathrm{H} 1 \mathrm{~N} 1$ Influenza pandemic lasted over a period of more than a year and evoked with three major waves, invariably influenced by seasonal attributes. In relevance to that, it is still obscure that SARS-CoV-2 will not be comprehended by the seasonal variations or not. ${ }^{7}$ Therefore, it is too early to say that SARSCoV-2 will not surge back into the community. To be precise, the less 
number of cases reported is not a clear cut indicator of the scenario for future, keeping in mind the track record of the 1918 H1N1 influenza pandemic.

\section{From the mortality point of view}

Mortality or rate of caseation depends on the host- pathogen interaction with respect to the viral and host organism's evolutionary hierarchy. Indeed, the SARS-CoV-2 virus affects mostly the elderly section of the population, whereas, 1918 H1N1 influenza virus principally targeted the young to juvenile adults of the community. ${ }^{8}$ However, it is not surprising that elderly are the most vulnerable to be affected by infections, but this was not the case in 1918 H1N1 influenza pandemic. In fact, the young adults in their late 20 s were the major victims of $1918 \mathrm{H} 1 \mathrm{~N} 1$ influenza pandemic but the reason is still not yet clear enough. ${ }^{9}$ However, some section of modern day epidemiologists believe that exposure to the prior 1890 influenza pandemic might had made the victimized population "immunologically primed" and that was be one of the strong reasons behind such phenomenon. ${ }^{10}$ In case of 1918 H1N1 influenza pandemic mortality was majorly driven by secondary bacterial invasion (either by pneumococcal or streptococcal) after the influenza virus had completely demolished the respiratory epithelium of the host. ${ }^{11}$ On the other hand, SARS$\mathrm{CoV}-2$ or the ongoing global pandemic does severely affect age range of more than 60, the vulnerable ones are the males compared to the female counterparts. At the same regard, the victims are diagnosed with hypertension, diabetes, obesity and cardio-vascular disease. ${ }^{12}$ The influence of secondary infection is very critical for SARS-CoV-2 infection. The most susceptible age group for Covid-19 i.e. the age around 60 and above have been consistently depicted with respiratory distress, pulmonary compromise and multi-organ failure leading to death around the second week of the infection. However, the reason for the secondary infection is yet to be determined because most of the patients in intensive care units are treated with broad spectrum antibiotics. Moreover, there is every chance of those patients being affected by hospital-resident bacteria during the respective treatments in those units..$^{13}$ To be precise, irrespective of the mechanism a large number of casualties have been continuously evaluated across the vast geographical periphery around the globe.

\section{Infodemic:The most evident obstacle}

The most crucial facet of the ongoing global pandemic is the progressive dissemination of irrational information. With the advent and improvisations of digital networking and electronic media the global community has the access to explore and exchange the information with the tap of a finger. In fact, it undoubtedly has opened up a new level of sharing the idea, thoughts. ${ }^{14}$ However, it does have the negative counterpart too. Precisely telling, the digital media and social sites are the principle aids to propagate the misleading and vague information across the community, ${ }^{15}$ as they go for mass sharing of information ${ }^{16}$ but mostly without authentic and legalized monitoring protocols. ${ }^{17}$ Indeed, this has been the major reason behind the false information being dispersed on a large-scale over a period of time. If we could date back to the global pandemic of $19^{\text {th }}$ century we would be able to assess that there were three significant factors that eventually propelled the pandemic in uncontrollable proportion. Firstly, the common people were extremely indifferent regarding the risk and severity of the degree of infection. Secondly, the people were very much tentative about the necessary measures in order to squeeze the spread of the infection. The third and of utmost importance was the lack of awareness among the common people regarding the mode of transmission of the 1918 H1N1 Influenza virus during the period of crisis from 1918 to 1919. In relevance with that, an array of fallacious information has been disseminating thick and fast including the continuous intake of oregano, bleach and cleaning the facial parts with the salty water to name a few. ${ }^{18,19}$ In fact, such preposterous notions are replicating into people's mindset and at the same regard, escalating the degree of Covid-19 pandemic to several notch as far as the infodemic is concerned. In addition to that, the rapidly propagated stories across the electronic media regarding the potential basis of the infection like the concept of intake of 'bat soup' might be the cause of the outbreak has been equally contributing to the fallacy. ${ }^{20}$

At the same point, we cannot dislodge the influence of social media, especially, Facebook, Twitter as well as YouTube to propagate the fake news throughout the global community since the onset of the ongoing pandemic. In reality, not enough filtering and various loopholes regarding the monitoring of the transmission through the digital media about the news of Covid-19 pandemic at the onset were the other contributing factors. ${ }^{21}$

\section{Discussion}

A. In addition to the ongoing global pandemic of Covid-19 this millennium is also the era of the resounding number of psychological disorders. ${ }^{22}$

B. It is quite evident that the ongoing Covid-19 pandemic has appreciably added a new dimension by the remarkable divergence as far as the infodemic is concerned. In fact, WHO has already taken sizable measures to filter out the fallacious information regarding the SARS-CoV-2 virus in order to restrict the dissemination of fake news/stories across the global community. ${ }^{23}$

C. In addition, WHO has also established a daily repository to propagate the authentic information from the official website. ${ }^{24}$

D. However, to find out the precise therapeutics of the ongoing global pandemic is another daunting task. Since last few months or so scientific fraternity around the world has been deeply involving themselves in finding the best possible way out to combat this deadly enemy. In relevance to that, Convalescent plasma (CP) therapy might be one of the potential remedies to derail the further outbreak Covid-19 pandemic. Over the last few decades this technique has been used successfully to curtail down the spread of several infectious diseases including SARS, ${ }^{25}$ MERS and 2009 H1N1 influenza pandemic. ${ }^{26}$

E. To add to it, several countries across the wide geographical periphery have been advocating about the Convalescent plasma $[\mathrm{CP}]$ therapy, bearing in mind that there are not proven therapeutics available for the Covid-19 specific treatment currently to secure the lives of the infected ones. However, to captivate the efficacy of the $\mathrm{CP}$ therapy health care professionals must take into account both the patient as well as the donor eligibility. In addition to the tried and tested CP therapy scientists across the world have been trying the level best to search for alternatives. The quest started with the application of anti-malarial drugs such as, Chloroquine, Hydroxychloroquine. Since then other pharmaceuticals like- Ivermectin, Remdesivir have been also implied in several clinical trials to find out the appropriate remedy.

F. Since the very beginning of the human civilization a chronicle of viral diseases marked their effects on the mankind. In fact, before the ongoing SARS-CoV-2 pandemic, viruses like Small Pox, severely catastrophized the societal image of the 
respective times. However, mankind came out from the very dark to the new dawn with the discovery of vaccines against such viruses.

G. The principle objective of the scientific fraternity right now is to develop the vaccine of the novel SARS-CoV-2 to repair the damage whatever has been done. Indeed, it is a stiff mountain to climb, but humankind has done this in the past. However, to develop vaccines against such deadly virus is a herculean task and it will need at least few months, years.

H. Moving forward, special care and attention should be given to lift the tempo of the health system of the community that has been reeling since last few months or so by the logarithmic growth of the negative version of the infodemic. To resurrect the image of the social media people of all the socio-economic strata has to take the initiative.

I. Designated web portals, public helplines should be implemented to wipe out the psychological stigma, distress whatever existing at the public level regarding the ongoing global pandemic. It should be a practice to make the best use of the social media to make the civilians educated enough, realistic and responsible to take the correct steps at the right moment.

J. At the same regard, robust Govt. laws and regulatory policies should be adhered to dislodge any fake news, rumors, stories about the Covid-19 pandemic. The negative infodemic already has reached the level of alarming proportion and caused significant loses. Therefore, it is extremely vital to combat against such infodemic as we have been fighting against the SARS-CoV-2.

\section{Conclusion}

The ongoing Covid-19 pandemic has already taken the lives of more than 4.65 million people globally along with another nine million infected cases. To say the least, this catastrophic incidence is not only a health crisis, rather, it is a socio-economic curse. In fact, the effects will be remaining in the global community in future decades. However, the silver lining among the dark clouds is the significant increase in the ratio of rate of infected cases versus the rate of recoveries. To be honest, people around the globe are finding themselves in a state of relative comfort by seeing this positive ratio, especially, since last month or so, having said that, we cannot still rule out the possibilities of second and third waves of the Covid-19 pandemic. If we could date back, the 1918 H1N1 Influenza pandemic headed across the world with the influence of three major spikes, primarily, due to climactic attributes during that period of time. Therefore, it is not the time to be completely lenient regarding the lifting of the measures is concerned. At the same time, new and potential therapeutics to combat the novel Covid-19 virus should be recommended into practice, provided much more clinical trials will be manifested. Furthermore, global electronic media should be more proactive to propagate the exact infodemic about the ongoing global pandemic across the community. Last but not the least, it is not the time to be divided, in reality, it is the moment to think holistically to make sure that future humankind will survive and sustain, defeating the odds of SARS-CoV-2.

\section{Acknowledgments}

None.

\section{Conflicts of interest}

The author declares that there is no conflict of interest to disclose.

\section{Funding}

None.

\section{References}

1. Robert L Atmar, Antone R Opekun, Mark A Gilger, et al. Norwalk Virus Shedding after Experimental Human Infection. Emerging Infectious Diseases. 2008;14(10).

2. Markel H Lipman, Harvey B Navarro, Alexander AJ. Et al. Nonpharmaceutical Interventions Implemented by US Cities During the 1918-1919 Influenza Pandemic. Journal of American Medical Association. 2007;98(6):644-654.

3. Mueller J Johnson, Niall PAS. Updating the Accounts: Global Mortality of the 1918-1920 "Spanish" Influenza Pandemic. Bulletin of the History of Medicine. 2002;76(1):105-115.

4. Long S Jason, Mistry B, Haslam M, et al. Host and viral determinants of influenza A virus species specificity. Nature Reviews; Microbiology. 2019;17(67).

5. Sanjuan R, Nebot R Miguel, Nicola C, et al. Viral Mutation Rates. Journal of Virology. 2010;84(9): 9733-9748.

6. Lofgren E, Fefferman NH, Naumov YN, et al. Naumova. Influenza Seasonality: Underlying Causes and Modeling Theories. Journal of Virology. 2007;81(11):5429-5436.

7. Verity R, Okell LC, Dorigatti I, et al. Estimates of the severity of coronavirus disease 2019: a model-based analysis. Lancet Infect Dis. 2020 .

8. Morens DM, Fauci AS. The 1918 influenza pandemic: insights for the $21 \mathrm{st}$ century. J Infect Dis. 2007;195(7):1018-28.

9. Gagnon A, Miller MS, Hallman SA, et al. Age-specific mortality during the 1918 influenza pandemic: unravelling the mystery of high young adult mortality. PloS one. 2013;8(8).

10. Morens DM, Taubenberger JK, Fauci AS. Predominant role of bacterial pneumonia as a cause of death in pandemic influenza; implications for pandemic influenza preparedness. J Infect Dis. 2008;198(7):962-970.

11. Zhou F, Yu T, Du R, et al. Clinical course and risk factors for mortality of adult inpatients with COVID-19 in Wuhan, China: a retrospective cohort study. Lancet. 2020;395(10229):1054-62.

12. Li H, Liu L, Zhang D, et al. SARS-CoV-2 and viral sepsis: observations and hypotheses. Lancet. 2020.

13. Rapid Expert Consultation on SARS-CoV-2 Survival in Relation to Temperature and Humidity and Potential for Seasonality for the COVID-19 Pandemic. The National Academies Press, National Academies of Sciences, Engineering, and Medicine. 2020.

14. Del Vicario M, Bessi A, Zollo F et al. The spreading of misinformation online. Proceedings of the National Academy of Sciences of the United States of America. 2016;113(3):554-559.

15. Lazer DMJ, Baum MA, Benkler Y et al. The science of fake news. Science. 2018;359(6380):1094-1096.

16. Vosoughi S, Roy D, Aral S. The spread of true and false news online. Science. 2018;359(6380):1146-1151.

17. Lewandowsky S, Ecker UKH, Seifert CM et al. Misinformation and its correction: Continued influence and successful debiasing. Psychological Science in the Public Interest. 2012;13(3):106-131.

18. Chakravorti B. As coronavirus spreads, so does fake news. Bloomberg Opinion. 2020.

19. Taylor J. Bat soup, dodgy cures and 'diseasology': The spread of coronavirus misinformation. The Guardian. 2020. 
20. Aguilera J. Xenophobia 'is a pre-existing condition'. How harmful stereotypes and racism are spreading around the coronavirus. 2020.

21. Rubio Hancock J. Las redes sociales y Google intentan contener la desinformación y el. Pánico sobre el coronavirus. El País, 2020.

22. World Health Organization. Novel Coronavirus (2019-nCoV). 2020.

23. World Health Organization. Novel Coronavirus (2019-nCoV) advice for the public: Myth-busters; 2020.
24. Mair Jenkins J, Saavedra Campos M, Baillie JK, et al. The effectiveness of convalescent plasma and hyperimmune immunoglobulin for the treatment of severe acute respiratory infections of viral etiology: a systematic review and exploratory meta-analysis. J Infect Dis. 2015:211(1):80-90.

25. Duan K, Liu B, Li C, et al. Effectiveness of convalescent plasma therapy in severe COVID-19 patients. Proc Natl Acad Sci USA. 2020.

26. Dana Sparks. Convalescent plasma: A therapy for COVID-19, 2020. 